\title{
Impact Of Computerized Accounting Information System On Small And Medium Enterprises In Mogadishu, Somalia: The Balance Scorecard Perspectives
}

\author{
AbdiSalam Salad Abdulle, Zaini Zainol, Hawa Ahmad
}

\begin{abstract}
Information, communication and technology (ICT) adoption has increased dramatically over time irrespective of organizations, be public or private, profit or not for profit organizations around the world. No doubt that ICT investment will spur economic growth as studied done by many countries. The African Union Agenda 2063 has acknowledged the importance of digital inclusivity for African countries to be on par with the rest of the world as an information society. African nation and Somalia particularly have still some challenges to deploy ICT on the concern of availability, accessibility and affordability. Nevertheless, in a business environment where businesses compete in the highly fragile market, ICT modernization in all business processes including accounting is a crucial tool for continuous improvement towards competitive services offered to customers. The implementation and adaption computerized accounting systems (CAIS) for any organization such as SMEs will enable the management and owners to improve decision making, internal controls and financial information, as well as enable financial reporting to be designed and processed on a standardized format and timely. It was reported that the use of inefficient information to support financial decision making and poor quality and reliability of financial information were part of the major SMEs challenges. Therefore, this study attempts to understand the usage of CAIS and its impact on the performance of SMEs in Somalia. The survey questionnaire is designed and distributed to selected SMEs in the capital city of Mogadishu, Somalia. The results of CAIS's impact are discussed from four components of balanced scorecard namely financial, customer, internal processes and learning \& growth perspectives. The results of this study may provide knowledge about the impact of usage CAIS for SMEs performance in Somalia
\end{abstract}

Keywords: Computerized accounting information system, financial perspective, customer perspective, internal processes perspective, learning \& growth and small and medium enterprises.

\section{INTRODUCTION}

Information, communication, and technology (ict) adoption has increased dramatically over time irrespective of organizations, be public or private, profit or not for profit organizations around the world. No doubt that ict investment will spur economic growth as studied done by many countries. For example, japan 2015 white paper on

Revised Manuscript Received on April 19, 2019.

AbdiSalam Salad Abdulle, Post Graduate Unit, KENMS, International Islamic University, Kuala Lumpur, Malaysia.

Zaini Zainol, Department of Accounting, KENMS, International Islamic University, Kuala Lumpur, Malaysia.

Hawa Ahmad, Department of Accounting, KENMS, International Islamic University, Kuala Lumpur, Malaysia. information and communication indices reported if small businesses can fully adopt ict technologies, they will be able to create about 200,000 jobs. Elsewhere, the african union agenda 2063 has acknowledged the importance of digital inclusivity for african countries to be on par with the rest of the world as an information society. African nation and sudan particularly have still some challenges to deploy ict on the concern of availability, accessibility, and affordability. Nevertheless, in a business environment where businesses compete in the highly fragile market, ict modernization in all business processes including accounting is a tool for continuous improvement towards competitive end product or services offered to customers The revolution in information technology has changed the nature of business in small or medium-sized businesses. Ecommerce has made it possible to cross border transactions being carried out. As understood by the business community, accounting information is regarded as a business language and processing daily business transactions are highly important for efficient and effective business decision. Towards making this information readily available in various forms as needed by users such as financial statements and various reports, the implementation and adoption of the proper accounting system are crucial for the future success of any business, regardless of the size of the industry such as in small and medium enterprises (sibley, 1998).

Nowadays, with various affordable accounting software available in the market such as UBS, Sage, etc., more businesses had adopted these applications. In Somalia, SMEs constitute the larger part of the private sector with specific reference to their numbers and employment figures (Abdi nor, 2013). SMEs are gradually taking the role of the fundamental vehicles for income generation and the creation of employment by self-employment and tools for poverty alleviation. Recognizing the role small businesses in the Somali economy, the United Nations Development Program through the Economic Foundations predicts the strengthening of SMEs to become the key industries of tomorrow by improving their productivity and innovation through small business grants (UNDP, 2013). 
With constraint on well-trained manpower, SMEs are associated with the inefficiency in its administration and eventually affected the company's performance. As stressed by Padachi (2012), poorly accounting management together with other internal factors such as marketing and operation may be equally responsible for the poor performance of SMEs. Among the tasks in accounting, management is preparing a chart of accounts, general ledger, journals, and subsidiary journals, maintaining the integrity of an accounting system, types of the accounting system and other essential documents. These tasks require some modernization to make it more efficient. SMEs' ownermanager need a good accounting knowledge particularly on double entry record keeping system that allows them to maintain control of their finance (Davis et.al.,2009) and CAIS serves here as a good record -keeping system tool or technique. Hence CAIS adoption may be a decisive factor for an organization to be a success and survive. Therefore, this study attempts to understand the usage of computerized accounting information system and its impact on the performance of small medium enterprises in Somalia. Following the discussion above, the objectives of the study are designed as follows:

-To understand the current level of usage of computerized accounting Information systems (CAIS) of SMEs in Somalia as our first research objective.

-Using the Balanced Scorecard approach to investigate CAIS impact on the organizational performance by comparing higher adapters and lower adapters of CAIS for our second research objective.

\section{LITERATURE REVIEW}

\section{A. Background of CAIS}

Generally, CAIS originally came from evolution in accounting information systems (AIS), a system used to record business or economic activity movements. Gutierrez, et al (2011) defines AIS as account information system which refers to computer systems used for writing and processing business information, as well as producing reports to help management plan and control business activities. Whereas, a computerized accounting software deals with the software that used to process the work of accounting information systems which developed for the purpose of easier in making the decision making.

These are created due to several advantages such as fastness of carrying out routine accounting information, appropriate time consumed, quick data analysis, accuracy financial statements and reporting. Effective and efficient information flow, thereby increasing the firm's capacity to achieve corporate and business strategy objectives (Manson, McCartney, and Sherer, 2001). In another study, Ury (2011) defines computerized accounting system (CAS) as accounting done with the aid of a computer that trends to involve dedicated accounting software and digital spreadsheets to keep track of a business or client's financial transactions.
A computerized accounting system, therefore, involves the computerization of accounting information systems which is established to facilitate decision making. These are associated with several benefits like the speed of carrying out routine transactions, timeliness, quick analysis, accuracy and reporting (Amviko, 2011). According to Munashinge (2015), CAS broadly defined as a software tool for processing financial information of the business. For consistency, we grouped terms such as AIS, CAS, accounting software and accounting system into the computerized accounting information system (CAIS) so that a common term is used throughout this paper.

\section{B. CAIS and Its Impact on SME}

In line with technology evolving in the business landscape which affecting accounting information, significant interest among researchers attracted into this area has been reported. Various topics were researched and completed in computer-based information system and computer-based accounting information systems in their respective times.

Unlike in early years of studies which very much focus on computer application in accounting, the year 2000 onwards addressed more on factors affecting the implementation of computer (i.e. IT) or information system (IS) in the accounting system to the implemented organizations. Prior literature highlighted that many SMEs faced increased challenges in financial reporting which may lead to a failure (see Mc Mahon, 2001) and bookkeeping problem (see Porter and Milner, 1985). In view of this, there is a need to have a proper accounting system to facilitate financial management as stressed by Gorton (1999). Melanie, Steve, and Chris (2011) analyzed the part of the accounting information system in the organization of winery SMEs in Australia and concluded that accounting information plays an important role in the administration of SMEs. Changes in information are constant and therefore the use of technology is required in small businesses. Moreover, Urquia et al. (2011) also examined the impact of accounting information system on SMEs in Spanish and found out that the use of CAIS as defined in their study as AIS is crucial in order to broaden the market, enhance management of selling costs and improve firms' management of relations with customers and suppliers.

Elsewhere, Saira et al. (2010) examined "information system and firm performance of Malaysian SMEs using panel data". Using 205 firms as a sample, they gathered monetary statement information for five years times frame starting from the year 2004-2008. Results from regression analysis revealed that SMEs adopting AIS improve significantly in performance compared to non-adopters.

\section{CAIS and Its Impact on SME in Africa Region}

From another perspective, Olatunji (2013) studied the impact of CAIS or defined as AIS on SMEs performance in Oyo State, Nigeria. The study reviewed the degree accounting information system completed as well as analyzed the constraints of little and middle endeavors of 
SMEs to actualizing filled bookkeeping frameworks. The finding of this review recorded the positive impact of receiving sound bookkeeping frameworks on business execution. Prior to this, noted that poor accounting system, Ohachosim, Onwuchekwa and Ifeanyi (2012) assessed the degree of bookkeeping data can be utilized to improve the monetary difficulties of getting fund among SMEs in Nigeria. Akande, (2011), investigated how accounting skill of an entrepreneur is necessary for the success of small businesses of Nigeria based on survey research design. A simple random sampling technique used, a total of 140 small business owners from Ogun state was selected.

They concluded that owner-entrepreneurs should focus on improving accounting skill in financial management and record keeping for better results. Also, they suggested that the government of Nigeria should make it compulsory to prepare financial statement of small businesses to evaluate their performances in their business. Further, a study conducted by Kwame, Emmanuel, Eric and Oduro (2014) to investigated AIS on SMEs in Ghana used the Sunyani Municipality as a case study. They found among others, that some of the SMEs did not keep bookkeeping records.

\section{CAIS and Its Utilization in SME}

According to Taragola, et. al., (2001), the willingness to adopt accounting software is positively related to a favorable attitude towards accountancy and 'intrinsic objectives'. He further stated that the adoption of computerization is based on the business size, computer training of the firm manager, creativity and potential business growth. Subsequently, Zulkifflee (2013), examined the relationship between SMEs entrepreneurs' perceptions towards a proper accounting system with several variables such as the level of accounting staff recruited, preparation of final account and meeting with accounting staff. He found that there was an insignificant relationship between SMEs entrepreneurs' perceptions on the importance of a good accounting system and preparation of final accounts of the company and the frequency of meeting with accounting staff. In another study, Breen, et.al., (2003), in their study of computerized accounting systems in Australia, found that about 96 percent of the SMEs, install and use generalized packages ranging from mind- your- own- business (MYOB), Quick books, cash - flow manager and attaché.

\section{HYPHOTHESES}

This study examines the implementation of CAIS and its impact on firm performance. Specifically, the study investigates whether SMEs with higher adopters of CAIS have a more positive effect on the organizational performances than lower adopters of SMEs.

Therefore, in this study, SMEs which use specific CAIS is categorized as higher adapters whereas non-specific CAIS such as Excel is categorized as lower CAIS adapters as depicted in Figure 1. For specific CAIS, several software packages are available such as QuickBooks, Mind Your Own Business (MYOB), EPICOR (formerly Platinum), Tally ERP, PASTEL and SUN.

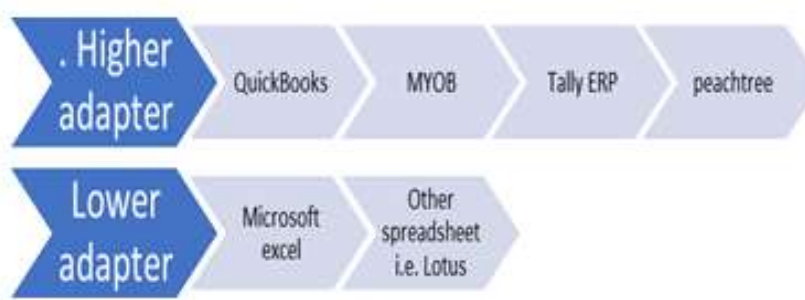

Figure 1: Category of SME According to the Level of Source: Own compilation CAIS Adoption

Hypotheses of the Study

We proposed four hypotheses as follows:

H1: SMEs with higher adapters of CAIS have a more positive effect on the financial perspective than lower adapters.

H2: SMEs with higher adapters of CAIS have a more positive effect on the customer perspective than lower adapters.

H3: SMEs with higher adapters of CAIS have a more positive effect on the internal processes perspective than lower adapters.

H4: SMEs with higher adapters of CAIS have a more positive effect on the learning and growth perspective than lower adapters.

\section{RESEARCH METHODOLOGY}

The area of the study is Mogadishu city whereby small medium enterprise in Mogadishu City was surveyed. The study makes use of a descriptive survey research design. This study comprised Small medium enterprises in Mogadishu City. The study selects and collect data from 372 out of 11, 569 registered enterprises in Mogadishu, Somalia using purposive sampling technique. The data were collected through an electronic survey via Google Form questionnaire. The questionnaire was divided into three sections. Section "'A", Background of the study, Section "B" about Challenges of computerized accounting information system and section "C" dealt with Organizational performance. Items are measures between 1 (strongly disagree) to 5 (strongly agree).

\section{RESULT AND DISCUSSION}

\section{A. Descriptive Analysis}

A total of 372 questionnaires were emailed to the respondents and 253 questionnaires were returned. As shown in Table 1, for "Years in the company" $30.4 \%$ respondents are more than 10 years, $53.4 \%$ between $5-10$ years and $16.2 \%$ indicated less than 5 years. Since the majority of respondents have more than 5 years working experiences, they are expected to possess the competency, skills and knowledge about their jobs, which might increase the accuracy and reliability of responses. The next item, "Type of business" shows manufacturing recorded 3.6\%, trading $52.6 \%$ while service is $37.9 \%$. This result shows that a majority of respondents are involved in the trading 
business. For the third item which is gender only $29.2 \%$ of respondents are female while $70.8 \%$ are male.

In term of level of CAIS adoption, the number of SMEs that have higher CAIS adapted is more than lower CAIS adapted. The result shows $77.5 \%$ of SMEs were higher CAIS adapted and only 57 SMEs or $22.5 \%$ were lower implementation", $74.3 \%$ responded more than 5 years as compared to $25.7 \%$ below 5 years. This indicated that most of SMEs participating in this study have achieved the maturity level of CAIS implementation.

Table 1

\begin{tabular}{|l|c|c|}
\hline $\begin{array}{c}\text { Demographic } \\
\text { variables }\end{array}$ & $\begin{array}{c}\text { Frequenc } \\
\mathbf{y} \mathbf{\text { ne253 }}\end{array}$ & $\begin{array}{c}\text { Percenta } \\
\text { ge (\%) }\end{array}$ \\
\hline Years in the company & & \\
\hline Less than 5 years & 41 & 16.2 \\
\hline 5-10 years & 135 & 53.4 \\
\hline More than 10 years & 77 & 30.4 \\
\hline Types of business & & \\
\hline Manufacturing & 9 & 3.6 \\
\hline Trading & 133 & 52.6 \\
\hline Service & 96 & 37.9 \\
\hline Plantation & 15 & 5.9 \\
\hline Gender & & \\
\hline Male & 179 & 70.8 \\
\hline Female & 74 & 29.2 \\
\hline Adapting CAIS & 196 & \\
\hline Higher CAIS Adapters & 57 & 22.5 \\
\hline Lower CAIS Adapters & & \\
\hline $\begin{array}{l}\text { Years of } \\
\text { implementation }\end{array}$ & 65 & 25.7 \\
\hline Less than 5 years & 188 & 74.3 \\
\hline More than 5 years & \\
\hline$R$
\end{tabular}

\section{B. Independence Sample t-Test}

The financial perspective is measured using five items. The highest mean score is "Using CAIS reduces documentation cost" recorded scored 4.16, followed by "CAIS reduces administrative monitoring cost" mean score 4.13, "Reduce technology cost" with mean score 4.13, and "Reduced procurement cost" with a mean score of 4.12. The lowest rank is "CAIS increases the frequency of revenue collection", with a mean score of 4.04. Secondly, for customer perspective, mostly of respondents agreed that "CAIS improves service quality through customer direct feedback" with mean score 3.94, followed by "Using CAIS provides a platform for more interactive customer service" with mean score 3.85 . The least score item is "Using CAIS helps to reduce the number of customers' complaint" with a mean score of 3.62. Thirdly, for internal processes perspective consists of five measurement items. The highest score (4.19) is "Using CAIS helps to increase integration of applications and facilitates in realigning goal for all units/sections or departments" while the lowest score (4.09) is "Using CAIS helps to reduce the time for accounts closure". Finally, as for the learning and growth perspective, five items are measured. The highest score is "Using CAIS supports organizational growth to be more efficient and effective in delivering services" with mean score 4.12, and followed by "Using CAIS supports government agenda for CAIS adapted. Finally, with regards to "Years of CAIS

SME growth in Somalia" with mean score of 3.95, while the lowest impacted by CAIS is "Using CAIS helps staff to create new ideas in the job" with mean score 3.74.

\section{Further Analysis: Independent Samples T-Test}

The independent-samples t-test evaluates the difference between the means of two independent or unrelated groups. That is, to evaluate whether the means for two independent groups are significantly different from each other. The grouping variable divides CAIS into two mutually exclusive groups or categories, i.e. higher CAIS adapters or lower CAIS adapters, while the test variable describes each CAIS on some quantitative dimension such as test performance. The t-test evaluates whether the mean value of the test variable (e.g., test performance) for one group (Higher CAIS adapters) differs significantly from the mean value of the test variable for the second group (Lower CAIS adapters).

Table 2

\begin{tabular}{|c|c|c|c|c|c|}
\hline \multicolumn{6}{|l|}{ BS Perspective } \\
\hline & Adapting & CAIS & $\mathrm{N}$ & Mean & Std. Dev \\
\hline \multirow[t]{2}{*}{ Financial perspective } & $\begin{array}{l}\text { Higher } \\
\text { Adapters }\end{array}$ & CAIS & 196 & 20.94 & 1.886 \\
\hline & $\begin{array}{l}\text { Lower } \\
\text { Adapters }\end{array}$ & CAIS & 57 & 19.37 & 4.190 \\
\hline \multirow[t]{2}{*}{$\begin{array}{l}\text { Customer } \\
\text { perspective }\end{array}$} & $\begin{array}{l}\text { Higher } \\
\text { Adapters }\end{array}$ & CAIS & 196 & 15.50 & 3.145 \\
\hline & \begin{tabular}{|l} 
Lower \\
Adapters
\end{tabular} & CAIS & 57 & 13.51 & 4.054 \\
\hline \multirow[t]{2}{*}{$\begin{array}{l}\text { Internal } \\
\text { perspective }\end{array}$} & $\begin{array}{l}\text { Higher } \\
\text { Adapters }\end{array}$ & CAIS & 196 & 21.04 & 1.993 \\
\hline & $\begin{array}{l}\text { Lower } \\
\text { Adapters }\end{array}$ & CAIS & 57 & 19.35 & 4.681 \\
\hline \multirow[t]{2}{*}{$\begin{array}{l}\text { Innovation and } \\
\text { Learning Perspective }\end{array}$} & $\begin{array}{l}\text { Higher } \\
\text { Adapters }\end{array}$ & CAIS & 196 & 20.03 & 3.291 \\
\hline & \begin{tabular}{|l} 
Lower \\
Adapters
\end{tabular} & CAIS & 57 & 17.91 & 4.718 \\
\hline
\end{tabular}

Independent Samples T-Test to Compare Financial Perspective for Higher CAIS Adapters and Lower CAIS Adapters

Based on the result, it was found that there are statistically significant differences in the score for higher CAIS adapters $(M=20.94, S D=1.886)$ and lower CAIS adapters $(\mathrm{M}=19.37, \mathrm{SD}=4.190 ; \mathrm{t}(62.727)=2.750 \mathrm{p}=.008$, two-tailed). Therefore, the result of Independent Samples ttest a compare the means, there is a significant relation founded. Since there is a significant difference between higher CAIS adapters and lower CAIS adapters for the financial perspective, it can be concluded that higher CAIS adapters are experiencing more impact on the financial perspective. Details as presented in Table 2 and 3. Hence, hypothesis 1 is supported.

Independent Samples T-Test to Compare Customer Perspective for Higher CAIS Adapters and Lower CAIS Adapters

Based on the independent samples t-test conducted to compare the customer perspective scores for higher CAIS adapters and lower CAIS adapters, the study found that there are statistical significant differences in score for higher 
CAIS adapters $(\mathrm{M}=15.50, \mathrm{SD}=3.145)$ and lower CAIS adapters $(\mathrm{M}=13.51, \mathrm{SD}=4.054 ; \mathrm{t}(76.649)=3.421 \mathrm{p}=.001$, two-tailed) as depicted in Table 2 and 3 respectively. Since there is significant difference between higher adapters and lower adapters for customer perspective, it can be concluded that higher CAIS adapters are experiencing more impact than lower CAIS adapters. So, the hypothesis 2 is supported.
Independent Samples T-Test to Compare Internal Processes Perspective for Higher CAIS Adapters and Lower CAIS Adapters

Table 2 and 3 shows the result for independent samples ttest conducted to compare the internal business perspective scores for higher CAIS adapters and lower CAIS adapters. The study found that there are statistically significant differences in score for higher CAIS adapters $(\mathrm{M}=21.04$, $\mathrm{SD}=1.993)$ and lower CAIS adapters $(\mathrm{M}=19.35, \mathrm{SD}=4.681$; $\mathrm{t}$

$(62.012)$

\begin{tabular}{|c|c|c|c|c|c|c|c|c|c|c|}
\hline & \multicolumn{2}{|c|}{$\begin{array}{l}\text { Levene's Test for } \\
\text { Equality of } \\
\text { Variances } \\
\end{array}$} & \multicolumn{7}{|c|}{ t-test for Equality of Means } \\
\hline & & \multirow[b]{2}{*}{$\mathrm{F}$} & \multirow[b]{2}{*}{ Sig. } & \multirow[b]{2}{*}{$\mathrm{t}$} & \multirow[b]{2}{*}{ df } & \multirow{2}{*}{$\begin{array}{l}\text { Sig. } \\
\text { (2-tailed) }\end{array}$} & \multirow{2}{*}{$\begin{array}{l}\text { Mean } \\
\text { Diff. }\end{array}$} & \multicolumn{3}{|c|}{\begin{tabular}{|l|l} 
& $95 \%$ Confidence \\
Interval of the \\
Std. Error Difference
\end{tabular}} \\
\hline & & & & & & & & Diff. & Lower & Upper \\
\hline \multirow[t]{2}{*}{$\begin{array}{l}\text { Financial } \\
\text { perspective }\end{array}$} & $\begin{array}{l}\text { Equal variances } \\
\text { assumed }\end{array}$ & 29.300 & .000 & 4.038 & 251 & .000 & 1.570 & 389 & .804 & 2.336 \\
\hline & $\begin{array}{l}\text { Equal variances not } \\
\text { assumed }\end{array}$ & & & 2.750 & 62.727 & .008 & 1.570 & .571 & .429 & 2.712 \\
\hline \multirow[t]{2}{*}{\begin{tabular}{|l|} 
Customer \\
perspective
\end{tabular}} & $\begin{array}{l}\text { Equal variances } \\
\text { assumed }\end{array}$ & 10.487 & .001 & 3.927 & 251 & .000 & 1.991 & .507 & .993 & 2.990 \\
\hline & $\begin{array}{l}\text { Equal variances not } \\
\text { assumed }\end{array}$ & & & 3.421 & 76.649 & .001 & 1.991 & .582 & .832 & 3.150 \\
\hline \multirow{2}{*}{\begin{tabular}{|l} 
Internal \\
business \\
perspective
\end{tabular}} & $\begin{array}{l}\text { Equal variances } \\
\text { assumed }\end{array}$ & 34.115 & .000 & 3.965 & 251 & .000 & 1.685 & .425 & .848 & 2.522 \\
\hline & $\begin{array}{l}\text { Equal variances not } \\
\text { assumed }\end{array}$ & & & 2.649 & 62.012 & .010 & 1.685 & .636 & .413 & 2.956 \\
\hline \multirow{2}{*}{\begin{tabular}{|l} 
Innovation and \\
Learning \\
Perspective
\end{tabular}} & $\begin{array}{l}\text { Equal variances } \\
\text { assumed }\end{array}$ & 20.237 & .000 & 3.848 & 251 & .000 & 2.118 & .550 & 1.034 & 3.202 \\
\hline & $\begin{array}{l}\text { Equal variances not } \\
\text { assumed }\end{array}$ & & & 3.173 & 72.550 & .002 & 2.118 & .668 & .788 & 3.449 \\
\hline
\end{tabular}

Table 3

\section{DISCUSSION}

This study addresses the impact of CAIS on SMEs performance in Mogadishu, Somalia. Data were collected using an online survey. Using the statistical package for the social sciences (SPSS) as a statistical tool for data analysis, data were analyzed through several tests, such as frequency and descriptive analysis, and Independent sample t-test model for comparing means score. As the research objective 1 is already explained in the descriptive analysis above, the following subsections discuss the findings for research objective 2 in details.

\section{The Effect of CAIS on the Financial Perspective}

The result of the study presented in the previous sections was carried out to determine the relationship between CAIS and financial perspective with the overall score is 4.12 . The results have supported $\mathrm{H} 1$ as a significant relationship between the two variables. Independent sample t-test shows a significant relationship between higher CAIS adapters and financial perspective than lower CAIS adapters. Since CAIS technology is expected to provide more timely and accurate enterprise-wide information for decision-making, the documentation cost and the administrative cost of the organization are expected to be reduced. The result of this study supported the prior studies that have shown the impact of CAIS implementation towards a financial perspective.
According to D and Amnim (2013), the result from their study shows that information technology makes financial reporting more accurate, useable and better. Moreover, accounting information systems (AIS) has a direct impact on the profitability level of small-scale businesses. Further, data is easily classified in a more detailed way which resulted in time-saving (Muhindo, Mzuza, \& Zhou, 2014).

\section{The Effect of CAIS on Customer Perspective}

The customer perspective is another factor investigated through analysis. The results show that the significant relationship between CAIS and customer perspective with an overall mean score of 3.76. Further analysis indicated that higher CAIS adapters reported a significant impact on customer perspective than lower CAIS adapters. The result of this study supported the prior researches that have shown the impact of CAIS implementation towards the customer perspective. According to Gorla et al. (2010), high-quality information such as relevancy, accuracy, and completeness are to be able to improve organizational impact in term of market information support such as customer needs and internal organizational efficiency. Moreover, Urquia et al.

Published By:

Blue Eyes Intelligence Engineering

\& Sciences Publication 
(2011) found out that the use of AIS is crucial to broaden the market, enhance management of selling costs and improve firms' management of relations with customers and suppliers.

\section{The Effect of CAIS on Internal Processes Perspective}

The third hypothesis of the study conducted in the impact of CAIS on internal processes perspective. The results of this study support the third hypothesis which states higher CAIS adapters has a significant impact on the internal business perspective. In terms of Internal business perspective, the result indicated overall mean score, 4.13 and this is the highest among all perspective. "Using CAIS helps to increase integration of applications and facilitates in realigning goal for all units/sections or departments" scored the highest mean 4.19. Prior studies suggested that the implementation CAIS leads to individual productivity while supporting the decision-making process made by staff (Wixom \& Watson, 2010). Also, the use of modern technology influences how a task is performed and what the outcome might be (Torkzadeh et al., 2005).

The result of this study supported the prior researches that have shown the impact of CAIS implementation on internal processes perspective. Clark, et.al., (2015) revealed that most of the SMEs with their computerized accounting system are able to finish jobs more efficiently. Whereas, Khar (2014) stated in his study that a computerized accounting system has a great potential to increase productivity, streamline workflow, reduce data redundancy and error reconciliation, and help with financial management. Also, Velcu (2007) who found that companies implementing CAIS experienced an enhancement of service time in accounting and reduce the time for accounts closure.

Overall mean score reported is 3.91 and "Using CAIS supports organizational growth to be more efficient and effective in delivering services" scored the highest mean i.e. 4.12. Further independent sample t-test revealed SMEs with higher CAIS adapters enjoyed more benefits than lower CAIS adapters. The result of this study supported the prior researches that have shown the impact of CAIS implementation such as Ismail and Kendari (2012) who stated CAIS has a positive relationship to individual job performance.

\section{RECOMMENDATION}

Overall, among these four perspectives of the balanced scorecard, the most reported impact is internal processes improvement (average mean is 4.13 ), then follows closely by financial perspective (4.12) and learning \& growth scored 3.91. The impact on customer perspective received the lowest score of impact, which is recorded overall 3.76. The findings of this study contribute to the existing body of knowledge on the impact of CAIS on SMEs performance in Mogadishu, Somalia. The information produced by assessing the impact of a computerized accounting system on SMEs performance could be utilized to propose future research in this area. Also, this will bring new guideline for CAIS adopters, educators, and researchers. Indeed, SMEs are strongly encouraged to continuously invest in ICT

\section{The Effect of CAIS on Learning and Growth Perspective}

especially advanced CAIS as the result shows higher CAIS adapters are getting more benefits than lower CAIS adapters. Nevertheless, as far as ICT is concerned, the government of Somalia must put more efforts, financial aid, better ICT policy, and encouragement to spur ICT penetration in Somalia.

\section{REFERENCES}

1. Abdi nor. (2013). The effect of microfinance institution lending on the growth of small and medium m enterprise in Somalia. Thesis of a Master of Science in finance degree, school of business, university of Nairobi.

2. Akande ,Olusola,O. (2011). Accounting skills as a performance factor for small businesses in Nigeria. Journal of emerging trends in economics and management sciences (JETEMS) Vol. 2, No. 5, pp. 372 378, (C) Scholarlink research institute journals 2011( ISSN-2141-7024).

3. Amviko, Agnes. (2011). Computerised accounting systems and financial reporting: A case of national water and sewerage corpor ation, Mbale branch, A research report, Makerere University, Kampala, p.1.

4. Breen, Nick Sciulli, and Cheryl Calvert. (2003). The Use of Computerized Accounting System in Small Business. 16th Annual Conference of Small Enterprise Association of Australia and new Zealand, pp. 1-12.

5. Clark Kent Arcega, Emerenciana D., Jessica G., Claudette G., Hanna J. M., Evangeline V., Jiexel L. M. (2015). Computerized vs. Non- computerized accounting system of small and medium enterprises in Lipa city, Philippines. A comparative analysis, Asia Pacific journal of academic research in business administration. Vol.1, No.1, April, pp.48-55.

6. Gorton, M.. (1999). Use of financial management techniques in the U.K. - Based small and medium enterprise. Empirical Research Findings. Journal of financial management and analysis, Vol. 12, No.1, pp.5161.

7. Gorla, N., Somers, T. M., \& Wong, B. (2010). Organizational impact of system quality, information quality, and service quality. The Journal of Strategic Information Systems, 19(3), 207-228.

8. Guitierrez, M., Lim, W., Ong, K.andYu, N. (2011). A study on the determinants of computerized accounting systems by SMEs in SM City North Edsa,Quezon City, Philippines. Working paper [online] Available at: http://www.docstoc.com/docs/124271106/FINALTHESIS-081909.

9. Ismail, N.A. and King, M. (2005) Firm performance and AIS alignment in Malaysian SMEs. International Journal of Accounting Information Systems. vol. 6, no. 4, pp. 241-259.

10. Ismail, N.A. and King, M.,2007. Factors influencing the alignment of accounting information systems in small and medium sized Malaysian manufacturing firms Journal of Information Systems and Small Business, 1(1) pp.1-20.

11. Ismail, N. A. (2009). Factors Influencing Ais Effectiveness Among Manufacturing Smes: Evidence From Malaysia. The Electronic Journal of Information Systems in Developing Countries, 38(10), 1-19.

12. Khar R. (2014). Computerized accounting system', Random Publications. New Delhi, ISBN 978-93-5111229-7.

13. Kwame, O. A., Emmanuel, O. M, Eric, N. G. \& Oduro, 
G. (2014). Accounting records keeping practices of SMEs in Ghana: Evidence from Sunyani Municipality. British Journal of Economics, Finance and Management Sciences. 9(1), 120 - 142.

14. Manson,S.,McCartney,S.andSherer,M.(1997),AuditAuto mation:TheUseOfInformationTechnologyinthePlanning, ControllingandRecordingofAuditWork,InstituteofCharter edAccountantsofScotlandResearchReport,Edinburgh.

15. Mc Mahon, (2001). Business Growth and performance and the financial reporting practices of Australian manufacturing SMEs. Journal of small business management Vol. 39, No. 2, pp.152-164.

16. Muhindo, A., Mzuza, M. K., \& Zhou, J. (2014). Impact of Accounting Information Systems on Profitability of Small Scale Businesses: A Case of Kampala City in Uganda. International Journal of Academic Research in Management, 3(2), 185-192.

17. Munashinge. (2015). Factors influence on usage of computerised accounting system on small and medium scale enterprises. RajrataUniversity, Srilanka.

18. Olatunji, T. E. (2013). The impact of accounting system on the performance of small and medium scale Enterprise in Nigeria -A survey of small and medium enterprises in Oyo State Nigeria. International Journal of Business and Management Invention, 2(9) 17.

19. Ohachosim, C. I., Onwuchekwa, F. C., \& Ifeanyi, T. T. (2012). Financial challenges of small and medium scale enterprises in Nigeria: The relevance of accounting information. Review of Public Administration and Management, 1(9), 248 - 276.

20. Padachi. (2012). Factors Affecting the Adoption of Formal Accounting Systems by SMEs Factors Affecting the Adoption of Formal Accounting Systems by SMEs.

21. Pan, J.-N., \& Nguyen, H. (2015). Achieving Customer Satisfaction Through Product-Service Systems. European Journal of Operational Research, 247, 179-190.

22. Porter M., and Millar V.E. (1985). How information gives you competitive advantage. Harvard Business Review,Vol. 63, No. 4, pp. 149-160.

23. Saira, K., Zariyawah, M., \& Annuar, M. (2010). Information system and firm's performance. The case of Malaysian small and medium enterprise. International Business Research, 3(4), 28 - 35.

24. Sibley, Bette. (1998). Invest time in learning your accounting software. The Bizmonthly magazine, p. 1 downloaded from http://www.bizmonthly.com/news 1998/March/sibley.shtm/.

25. Taragola, N., Van Lierde,D. and Van huylenbroeck, G. (2001). Adoption of computers, internet, and farm accounting software at the glasshouse holding of the Belgium farm accountancy data network. Proceedings of the 'Third European Conference of the European Federation for information Technology in Agriculture, Food and the Environment -EFITA 2001'. Montpellier, France, pp. 669-674.

26. Torkzadeh, G., Koufteros, X., Doll, W.J. (2005). Confirmatory factor analysis and factorial invariance of the impact of information technology instrument. The International Journal of Management Science, 33, 107118.

27. Urquia, G. E., Perez, E. R., \& Munoz, C. C. (2011). The Impact of accounting Information System on performance measure: Empirical evidence in Spanish small and medium enterprise. The International Journal of Digital Accounting Research, 11(1), 25 - 43.

28. Ury . (2011). The basics of computerized accounting. Retrieved from Everest College (Canada) Website: http://news.everest. ca/post/ 2011/08/the-basics- ofcomputerized- accounting/\#. UnXUatLwnDR.

29. UNDP. (2013). Somali annual report.
30. Wixom, B., \& Watson, H. (2010). The BI-based organization. International Journal of Business Intelligence Research, 1, 13-28.

\section{AUTHORS PROFILE}

AbdiSalam Salad Abdulle is a researcher and postgraduate student at PG Unit, KENMS, International Islamic University Malaysia. He received his first degree in accountancy from SEMAD University, Somalia.

Zaini Zainol is a senior lecturer at Department of Accounting, KENMS, International Islamic University Malaysia. He received his $\mathrm{PhD}$ in Information Science from the University Malaya, Malaysia. He is a member of Malaysian Institute of Accountants since 2001. His research areas are accounting information system, strategic information management and digital innovation in financial management.

Hawa Ahmad@Mutalib is a senior lecturer at Department of Accounting, KENMS, International Islamic University Malaysia. She has a more than 20 years experiences in industry and academia. She obtained her $\mathrm{PhD}$ in System Architecture from the University of Salford, Manchester, United Kingdom. 